\title{
Intensity Classification of Drills for a Collegiate Women's Lacrosse Team: An Observational Study
}

Kathryn H. Alphin, Brynn L. Hudgins, Jennifer A. Bunn*

Department of Physical Therapy, Campbell University, PO box 1090, Buies Creek, NC 27506, USA

Corresponding Author: Jennifer A. Bunn, E-mail: bunnj@campbell.edu

\section{ARTICLE INFO}

Article history

Received: June 16, 2019

Accepted: July 18, 2019

Published: July 31, 2019

Volume: 7 Issue: 3

Conflicts of interest: None

Funding: None

\begin{abstract}
Background: Balancing training load helps prevent injury and maximize performance, but coaches do not often know the load or intensity of drills when making selections for practice. Objective: This study aimed to classify the drills of a women's collegiate lacrosse team into low, moderate, and high intensity categories. Methods: Twenty-five participants wore global positioning system (GPS) devices and heart rate (HR) monitors daily during team practice and scrimmage matches. The data collected was trimmed to reflect only the time the players practiced and then organized by drill. Mean HR, distance rate, and training impulse (TRIMP) scores were used to classify drills into tertiles: low, moderate, and high intensity. Results: A total of 56 unique drills were analyzed over 33 training days, with 24 drills considered moderate intensity, 17 drills were high intensity, and 15 drills were low intensity. By position, 17 drills were low intensity for the midfielders, followed by 16 for the attacker, and 12 for the defenders and goalies. The defenders had the highest number of moderate intensity drills with 27 , followed by the attackers with 24 , midfielders with 21 , and goalies with 17. Lastly, midfielders and goalies had the highest number of high intensity drills with 18, followed by attackers with 17, and defenders with 16 . Conclusions: These results will help the coaching and training staff manage workloads and potentially reduce risk of injury and overtraining by giving insight into the demands of each drill they require of their athletes.
\end{abstract}

Key words: Heart Rate, Distance, Athletes, Workload, Exercise, Global Positioning System

\section{INTRODUCTION}

Coaches in numerous sports have spent years trying to manage the effects of training and play have on athletes and teams while bettering overall performance. Recent research shows that acute to chronic (A:C) workload ratio concepts are a beneficial predictor of finding this balance for it helps predict athlete injury (Hulin, Gabbett, Lawson, Caputi, \& Sampson, 2016). Similarly, balancing the intensity of the demands put on athletes is vital for preventing exhaustion and reducing the risk of injury (Bourdon et al., 2017). To train their teams efficiently, coaches must combine intense training with adequate recovery and less intense activities to continuously push their athletes for optimal performance. Utilizing data gathered from global positioning systems (GPS), heart rate monitors, and rate of perceived exertion scores (RPEs) to dictate practice load, a coaching staff can better prepare their players for game day. To do this, coaches need to know how intense each practice drill is so as not to schedule practice sessions that are counterproductive. Classifying each practice drill by its workload demand is a crucial step to making practice safe and efficient.

Mobile GPS and heart rate monitoring technology collect player performance data during games and practices. Players wear mobile devices that monitor speed, distance, and movement patterns to determine their external physical load while heart rate monitors paired with RPE assessments provide insight into player's internal load (Cummins, Orr, O'Connor, \& West, 2013). This is becoming a popular approach as compared to video analysis which has more room for error in a fast paced game (Cunniffe, Proctor, Baker, \& Davies, 2009). Teams in rugby, soccer, Australian football, and others have used GPS and heart rate monitoring systems to examine the loads on their players (Cummins et al., 2013; Dalen, Ingebrigtsen, Ettema, Hjelde, \& Wisloff, 2016; Loader, J., Montgomery, P.G., Williams, M.D., Lorenzen, C., Kemp, J.G., 2012). GPS technology monitoring is viewed as the best method for measuring training load (Wing, 2018) and has been proven to be valid when determining movement patterns at various speeds (Cummins et al., 2013) in numerous sports. When paired with heart rate monitors and RPEs, GPS data can be used to effectively monitor athlete load and classify training drills. Elloumi et al. (2012) found a linear relationship between higher RPE scores and increased risk for injury, with similar studies providing evidence of RPE and GPS technology correlations being useful to assist coaches in their training across various sports (Conte, Kolb, Scanlan, \& Santolamazza, 2018; Gabbett et al., 2017). Heart rate monitors help visualize heart rate spikes 
in comparison to athlete movement recorded by the GPS. This pairing can map out the times when athlete load was the most intense. These measurements are vital as they give insight into how hard the cardiac system is working. The average heart rate represents the workload being demanded from the cardiac system at a given time during an activity. Training impulse (TRIMP) zones are determined by measuring how long a player's heart rate stays in a particular heart rate zone (e.g. zone 1-5). These zones allow another look at the workload on the heart, as higher heart rates indicate higher TRIMP zones (Wing, 2018). Once this data has been recorded, an estimate of the training load during each drill compared to the demands of a game can be made. Utilizing several different monitoring techniques for athletes, including GPS technology, an adequate representation of load can be acquired and classified based on intensity level.

Several studies have utilized multiple athlete monitoring techniques in research concerning rugby, soccer, and Australian rugby, but very little research has been done in the area of lacrosse or in female athletes (Cummins et al., 2013; Dalen et al., 2016; Loader, J., Montgomery, P.G., Williams, M.D., Lorenzen, C., Kemp, J.G., 2012). The lack of knowledge in this area of drill classification can inhibit coaching staff from fully understanding how intense the demands of each drill are in a given practice. The mounting evidence for closer monitoring of total athlete load suggests its necessity in keeping athletes safe (Bourdon et al., 2017). This study aimed to categorize lacrosse drills of a Division I women's collegiate team based on intensity levels using GPS technology, and heart rate assessment. Classifying each drill will enable coaches to make better adapted practice plans fitting the needs of their players. This is crucial when determining how to obtain optimal performance and where to draw the line before injury occurs. Demanding too much from exhausted players increases the risk of injury but demanding too little does not push the team towards improvement. Drill classification helps bridge this gap. This research provides insight for a more specific understanding of the intensity of various drills for the benefit of coaching staff and recovery of the athletes.

\section{METHODS}

\section{Participants and Study Design}

This was an observational study, and 25 Division I collegiate female lacrosse players participated in the study. Only individuals on the university varsity team were eligible for study participation. Dependent variables for the study were related to evaluating drill intensity and included heart rate, TRIMP, and distance rate measured during each practice of the team's off-season. The independent variable was the type of drill completed. The athletes were aware of the demands and responsibilities that encompassed the study and signed a consent form acknowledging their understanding. This study was approved by the university Institutional Review Board (CUIRB-IRB00005697).

\section{Intensity Evaluation}

VX Sport vests, GPS devices, and heart rate monitors (Wellington, New Zealand) were assigned to each athlete. Before every practice the devices were distributed and the heart rate monitor pads within each vest were wet for accurate heart rate data to be collected. GPS devices were turned on at distribution and attached to the vest. Participants carried out the training as prescribed by their coaches. GPS metrics and heart rate were recorded in each practice session with various drills including: footwork, skill-specific drills, small-sided games, and simulated game play. At the end of each session the devices were collected, turned off, and stored in a cool dry space. Data were uploaded from the devices using the VX Sport training tool, and each session trimmed to exclude inactive times. Sessions were further split into separate drills based on what was accomplished in each practice. Scrimmages were subdivided into "warm-up" and "scrimmage" data with the halftime trimmed out. Average heart rate (beats/min), distance rate $(\mathrm{m} / \mathrm{min})$, and TRIMP zones (arbitrary units, AU) were pulled from each drill by day. These metrics were chosen because there was a large variation in how much time was spent in each drill, and each of these variables are calculated relative to time.

\section{Statistical Analyses}

Means of each metric were calculated, and drills were then organized into tertiles for all three metrics and classified based on the intensity level from the statistics report of each drill. Depending on the results of each of the three metrics, drills were organized by percentile rank and placed in a low $(<34 \%)$, moderate $(34-66 \%)$, or high $(>66 \%)$ intensity level. Upon disagreement of intensities between the three metrics, intensity was selected based upon a two-thirds agreement. For example, when two or more of the measurements were in the lower $33 \%$ of the entire team's averages, the drill was considered low intensity. If two or more were above $66 \%$ the drill was considered high intensity with all others being of the moderate level. Drill intensities were classified for the team as a whole and for each position: midfielders $(n=12)$, attackers $(n=5)$, defenders $(n=6)$, and goalies $(n=2)$. No inferential statistics were used. All analyses were conducted using Microsoft Excel (Redmond, WA).

\section{RESULTS}

The participants were $19.7 \pm 1.2$ years old, $166.4 \pm 5.9 \mathrm{~cm}$ tall, and had a mean mass of $64.8 \pm 6.5 \mathrm{~kg}$. A total of 56 unique drills were analyzed by the whole team and by position. Data for each drill was collected anywhere from one to 17 sessions over 33 training days. For each drill classification, the average HR, TRIMP, and distance rate are shown in Table 1. These data indicate that both internal and external demands increased with each drill intensity classification. Specific drills for each intensity classification are shown in Tables 2-4. For the whole team 15 of the 56 drills analyzed were low intensity (Table 2), 24 were considered moderate (Table 3 ), and 17 were high intensity (Table 4). Each table 
is organized for drills by the whole team, but differences in drill intensity by position are indicated. Attackers showed 16 drills were low in intensity, 24 moderate, and 17 high intensity level. For defenders, 12 drills were low in intensity, 27 moderate, and 16 were high. Midfield players showed 17 drills as low in intensity, 21 moderate, and 18 high. Goalies showed 12 drills as low intensity, 17 moderate, and 18 as high. More drills were intense for goalies as compared to other positions.

\section{DISCUSSION}

This study aimed to categorize lacrosse drills of a Division I women's collegiate team based on intensity levels using GPS technology and heart rate assessment. The results indicate variation among different drills with many of the conditioning and team drills being categorized as high intensity, small-sided games categorized as moderate intensity, and drills related to stick work and individual skills categorized as low intensity.

This is the first study to provide a method of drill classification for intensity in the sport of lacrosse. These results are a unique tool coaches can use to tailor practice and individualize training sessions. Mean heart rate and TRIMP scores provide information about the cardiovascular and in-

Table 1. Mean and standard deviations for each evaluation metric for each intensity drill classification

\begin{tabular}{lccc}
\hline $\begin{array}{l}\text { Drill } \\
\text { intensity }\end{array}$ & HR (bpm) & TRIMP(AU) & $\begin{array}{c}\text { Distance rate } \\
(\mathbf{m} / \mathbf{m i n})\end{array}$ \\
\hline Low & $141.4 \pm 10.4$ & $47.9 \pm 15.6$ & $30.4 \pm 5.7$ \\
Medium & $149.4 \pm 6.2$ & $61.5 \pm 17.1$ & $39.5 \pm 9.0$ \\
High & $159.2 \pm 7.5$ & $63.2 \pm 19.0$ & $46.4 \pm 6.8$ \\
\hline
\end{tabular}

ternal loading of a drill, whereas distance rates allow coaches to examine how fast their players are working and see which drills provide a greater external load. Knowing which drills are more demanding for the team and each position is vital to create a training plan. This information is monumental for developing practice plans specific to the intensity and recovery needs of the team, as well as managing injury risk. Inappropriate increases or sudden decreases in workload lay the ground work for injury, as athletes are not prepared for the demands both physically and mentally (Wing, 2018). Knowing how the team reacts to each drill helps prevent over-training and in some cases could prevent undertraining (Gabbett, 2016; Gabbett, 2018). Understanding the demand of each drill is key to creating effective training plans. The numerical value helps affirm what coaches already know from experience, providing insight into some drills that previously were not recognized as high on the intensity scale.

This literature compliments previous work by Weaving et al. $(2014 ; 2017)$ that evaluated the effects of different training modes on measures of training load in rugby players. Specifically, Weaving evaluated how different methods of training - small-sided games, conditioning, and skill workaffected internal and external metrics. The results of the two studies revealed that using both internal and external metrics for evaluation is useful for the different training modes. The present study employed both internal (heart rate, TRIMP) and external (distance rate) measures to evaluate the intensity of each drill, and an increase in these loads with higher intensity drills are present, as shown in Table 1. Data from the present study can also be used to compliment programs evaluating the A:C workload of an athlete (Gabbett, 2016) or monitoring the increases in workload to reduce injury risk (Gabbett, 2018). The A:C workload ratio helps manage athlete training to prevent overtraining that increases the risk of

Table 2. Low intensity drills classified for the whole team and by position

\begin{tabular}{|c|c|c|c|c|c|}
\hline Drills & Frequency & Attacker & Defense & Midfield & Goalie \\
\hline Bucket Drill & 1 & & & & NA \\
\hline Clearing & 3 & & & & \\
\hline Draw Skill Work & 3 & & NA & & NA \\
\hline Gauntlet Stick Protection & 1 & & & & NA \\
\hline Footwork Split & 2 & M & & & $\mathrm{H}$ \\
\hline Hamster Drill & 1 & M & $\mathrm{H}$ & & \\
\hline Play Intro & 3 & & & & NA \\
\hline Reaction Drill & 5 & & M & & NA \\
\hline Shooting Drill & 4 & M & M & & \\
\hline Soccer Circle Stick Work & 1 & & M & & NA \\
\hline 3 Man Passing Lines & 2 & & & & \\
\hline $3 v 2$ & 1 & & & & \\
\hline $3 v 3$ & 1 & & & M & \\
\hline $4 v 3$ & 2 & & & & \\
\hline $4 \mathrm{v} 3$ Half the $8 \mathrm{M}$ & 2 & & $\mathrm{H}$ & & NA \\
\hline $5 \vee 4$ Settled & 1 & & & & \\
\hline
\end{tabular}

All drills listed above were classified as low intensity drills for the whole team. If a position showed a different level of intensity, this is indicated as such for moderate $(\mathrm{M})$ or high $(\mathrm{H})$. NA indicates that the position did not regularly participate in this drill 
Table 3. Moderate intensity drills classified for the whole team and by position

\begin{tabular}{|c|c|c|c|c|c|}
\hline Drills & Frequency & Attackers & Defense & Midfield & Goalie \\
\hline Clears for Time & 2 & & $\mathrm{~L}$ & & $\mathrm{~L}$ \\
\hline Contested Star Drill & 2 & $\mathrm{H}$ & $\mathrm{L}$ & & \\
\hline DAD Drill & 2 & & $\mathrm{H}$ & $\mathrm{H}$ & $\mathrm{L}$ \\
\hline Forward/Backward Partner Work & 1 & & $\mathrm{H}$ & & $\mathrm{H}$ \\
\hline Footwork & 4 & NA & & $\mathrm{L}$ & NA \\
\hline GB Formlines & 2 & & & & $\mathrm{H}$ \\
\hline $1 \mathrm{v} 1$ in the Midfield & 1 & & & & $\mathrm{H}$ \\
\hline Partners & 11 & & & & \\
\hline Read \& Feed & 3 & & & & \\
\hline Short 1v1 & 1 & & & & NA \\
\hline Shuttle Lines & 1 & $\mathrm{H}$ & & & $\mathrm{H}$ \\
\hline Star Drill & 3 & & & & $\mathrm{~L}$ \\
\hline Triangle Passing & 2 & $\mathrm{H}$ & & & $\mathrm{H}$ \\
\hline Zulu Live & 1 & $\mathrm{H}$ & $\mathrm{H}$ & & $\mathrm{H}$ \\
\hline $1 \mathrm{v} 1$ & 9 & & & & \\
\hline $2 \mathrm{v} 2$ & 5 & & & & \\
\hline 2v2 Hammer Drill & 2 & $\mathrm{~L}$ & & & $\mathrm{H}$ \\
\hline $4 \mathrm{v} 4$ & 1 & & $\mathrm{H}$ & & NA \\
\hline $4 \mathrm{v} 4$ Half the $8 \mathrm{M}$ & 1 & & $\mathrm{H}$ & $\mathrm{L}$ & NA \\
\hline $5 v 5 v 5$ & 6 & $\mathrm{H}$ & & $\mathrm{H}$ & \\
\hline 7v6 Transition & 1 & $\mathrm{~L}$ & & $\mathrm{H}$ & $\mathrm{H}$ \\
\hline $7 \mathrm{v} 7$ & 12 & & & $\mathrm{H}$ & \\
\hline $8 \mathrm{M}$ & 6 & & & & \\
\hline
\end{tabular}

All drills listed above were classified as moderate intensity drills for the whole team. If a position showed a different level of intensity, this is indicated as such for low $(\mathrm{L})$ or high $(\mathrm{H})$. NA indicates that the position did not regularly participate in this drill

Table 4. High intensity drills classified for the whole team and by position

\begin{tabular}{|c|c|c|c|c|c|}
\hline Drill & Frequency & Attacker & Defense & Midfield & Goalie \\
\hline Competitive Full Field Clears & 1 & $\mathrm{M}$ & $\mathrm{M}$ & & M \\
\hline Dodging Footwork & 3 & & M & M & NA \\
\hline Ladder Footwork & 1 & M & M & M & NA \\
\hline Perfect Passing & 4 & & & & \\
\hline Pressured Star Drill & 3 & & & & \\
\hline Shuffle Partner Passing & 3 & & M & & \\
\hline Speed LAX & 1 & & & & \\
\hline Stickwork Footwork & 2 & & M & & \\
\hline Stryf Footwork & 1 & NA & M & & \\
\hline Zig-Zag & 3 & & & & M \\
\hline 1-3-1 Field transition & 1 & & & & NA \\
\hline 2-3-2 Full Field transition & 2 & & & & M \\
\hline 4-3-4 Full Field transition & 1 & M & & M & \\
\hline 5v4 Transition & 2 & M & M & & M \\
\hline 6v5 Transition & 1 & M & & & \\
\hline 7v7 Contested Clears & 3 & & & & M \\
\hline 7v7 Transition & 5 & & & & $\mathrm{~L}$ \\
\hline
\end{tabular}

All drills listed above were classified as low intensity drills for the whole team. If a position showed a different level of intensity, this is indicated as such for low (L) or moderate (M). NA indicates that the position did not regularly participate in this drill 
injury, and reduce undertraining that typically results in the loss of fitness (Wing, 2018). For example, prior to or after a game a coach may want to have a lighter practice day to optimize recovery. Coaches could then opt for including more drills from the light intensity classification to help build the bulk of their practice. Alternatively, on days where athletes need to go full out, a coach may choose more drills from the high intensity classification. Data from the present study are unique because they provide another tool in a coach's toolbox for appropriate drill selection to both work on necessary skills and intentionally manage athlete load.

These data contribute a great deal of practicality in the day-to-day practice planning task of coaches thereby likely reducing the risk of injury from overtraining (Bowen, Gross, Gimpel, Bruce-Low, \& Li, 2019) and the risk of loss of fitness from undertraining (Akubat, Patel, Barrett, \& Abt, 2012; Manzi, Bovenzi, Franco Impellizzeri, Carminati, \& Castagna, 2013). As previously mentioned, to our knowledge, this is the first study to classify drills based on intensity for any sport, thus comparison of this information to previous literature is limited. However, we believe this information will be highly impactful to the lacrosse program that we work with, as well as providing a template for other sports and programs to create their own drill intensity classifications.

One limitation of this study was that two of the three metrics determining tertiles were heart rate based, putting goalies at a risk of scoring higher on intensity levels in drills. Their position demands frequent and sudden spikes in heart rate with every shot taken, explaining why the results of their data had a higher intensity response to drills where longer bouts of exercise were required. The limited frequency of data collected for each drill was also a limitation of the study. More data should be collected to provide a stronger representation of how athletes perceive these drills over a longer period of time. Lastly, we did not obtain RPE data for each drill. Drill RPE would provide a subjective intensity rating from the athlete's perspective and would strengthen the application of intensity information. Lastly, inferential analyses were not utilized in this study because it did not align with the purpose of this paper.

For better application of these data and for future research, comparing each drill's load in HR, TRIMP, and distance rate to game metrics would be useful. This information would not only help with athlete load management, but would also help to create a more purposeful game-like intensity in practice with drills that are known to mimic game intensities. Comparing intensities between drills and games may help coaches make more informed efficient choices for drill selection for practice. Further, comparisons to game data may be used to help realign the different intensity classifications. Creating intensity classifications relative to game intensity would also help coaches make more informed decisions for drill selections for practice.

\section{CONCLUSIONS}

All of these implementations of drill classification can help improve the knowledge and decision-making of the coaching community. Previously, intensity was likely assumed and guessed, and these results provide firm data for intensity and load rather than assumptions. Being able to understand the effects of the demands on each athlete, tailoring practices efficiently, and preventing injury, improve the coaching staff's ability to implement the most effective training programs for their team. For collegiate athletics, these findings can help better the well-being of individual athletes as coaches are working with them to improve their health while pushing them to be the best they can be. Further, methods for evaluating and organizing drills by intensity used in this study can be easily replicated in other sports programs with different metrics such as RPE and/or internal and external metrics.

\section{CONFLICT OF INTEREST}

The authors declare no conflict of interest.

\section{REFERENCES}

Bourdon, P. C., Cardinale, M., Murray, A., Gastin, P., Kellmann, M., Varley, M. C., Cable, N. T. (2017). Monitoring athlete training loads: Consensus statement. International Journal of Sports Physiology and Performance, 12(Suppl 2), S2161-S2170. doi:10.1123/ IJSPP.2017-0208

Conte, D., Kolb, N., Scanlan, A. T., \& Santolamazza, F. (2018). Monitoring training load and well-being during the in-season phase in national collegiate athletic association division I men's basketball. International Journal of Sports Physiology and Performance, 13(8), 10671074. doi:10.1123/ijspp.2017-0689

Cummins, C., Orr, R., O’Connor, H., \& West, C. (2013). Global positioning systems (GPS) and microtechnology sensors in team sports: A systematic review. Sports Medicine (Auckland, N.Z.), 43(10), 1025-1042. doi:10.1007/ s40279-013-0069-2

Cunniffe, B., Proctor, W., Baker, J. S., \& Davies, B. (2009). An evaluation of the physiological demands of elite rugby union using global positioning system tracking software. Journal of Strength and Conditioning Research, 23(4), 1195-1203. doi:10.1519/JSC.0b013e3181a3928b

Dalen, T., Ingebrigtsen, J., Ettema, G., Hjelde, G. H., \& Wisloff, U. (2016). Player load, acceleration, and deceleration during forty-five competitive matches of elite soccer. Journal of Strength and Conditioning Research, 30(2), 351-359. doi:10.1519/JSC.0000000000001063

Dalen, T., Ingebrigtsen, J., Ettema, G., Hjelde, G. H., \& Wisloff, U. (2016). Player load, acceleration, and deceleration during forty-five competitive matches of elite soccer. Journal of Strength and Conditioning Research, 30(2), 351-359. doi:10.1519/JSC.0000000000001063

Elloumi, M., Makni, E., Moalla, W., Bouaziz, T., Tabka, Z., Lac, G., \& Chamari, K. (2012). Monitoring training load and fatigue in rugby seven players. Asian Journal of Sports Medicine, 3(3), 175-184.

Gabbett, T. J. (2016). The training-injury prevention paradox: Should athletes be training smarter and harder? British Journal of Sports Medicine, 50(5), 273-280. doi:10.1136/bjsports-2015-095788 
Gabbett, T. J. (2018). Debunking the myths about training load, injury and performance: Empirical evidence, hot topics and recommendations for practitioners. British Journal of Sports Medicine, doi: bjsports-2018-099784

Gabbett, T. J., Nassis, G. P., Oetter, E., Pretorius, J., Johnston, N., Medina, D., Ryan, A. (2017). The athlete monitoring cycle: A practical guide to interpreting and applying training monitoring data. British Journal of Sports Medicine, 51(20), 1451-1452. doi:10.1136/bjsports-2016-097298

Hulin, B. T., Gabbett, T. J., Lawson, D. W., Caputi, P., \& Sampson, J. A. (2016). The acute: Chronic workload ratio predicts injury: High chronic workload may decrease injury risk in elite rugby league players. British Journal of Sports Medicine, 50(4), 231-236. doi:10.1136/ bjsports-2015-094817

Loader, J., Montgomery, P.G., Williams, M.D., Lorenzen, C., Kemp, J.G. (2012). Classifying training drills based on movement demands in Australian football. International Journal of Sports Science \& Coaching, 7(1), 57-68.

Weaving, D., Jones, B., Marshall, P., Till, K., \& Abt, G. (2017). Multiple measures are needed to quantify training loads in professional rugby league. International Journal of Sports Medicine, 38(10), 735-740. doi:10.1055/s-0043-114007

Weaving, D., Marshall, P., Earle, K., Nevill, A., \& Abt, G. (2014). Combining internal- and external-training-load measures in professional rugby league. International Journal of Sports Physiology and Performance, 9(6), 905-912. doi:10.1123/ijspp.2013-0444

Wing, C. (2018). Monitoring athlete load: Data collection methods and practical recommendations. Strength and Conditioning Journal, 40(4), 26-39. doi:10.1519/ SSC.0000000000000384 